\title{
Costus Root Extract Preserves Thyroid Hormones Levels, Thyroglobulin Expression and Thyroid Tissues in Rats Receiving Valproate Sodium
}

\author{
Marwa Salah Mahmoud* \\ Zoology Department, Faculty of Science, Beni-Suef University, Beni-Suef 62514, Egypt \\ ${ }^{*}$ Corresponding author. E-mail: marwa_salah78@yahoo.com \\ Received date: Jan 26, 2020; Revised date: Aug 18, 2020; Accepted date: Aug 31, 2020
}

\section{Abstract}

$\mathrm{B}$ ACKGROUND: Valproate sodium is an anticonvulsant drug. Saussurea lappa (costus) is a medicinal plant rich with antioxidants. This research aimed to assess the protective effect of costus root extract against valproate sodium-induced thyrotoxicity.

METHODS: Eighty adult male albino rats were equally divided into four groups; group I: untreated control, group II: rats were given $200 \mathrm{mg} / \mathrm{kg}$ BW valproate sodium orally and daily for 8 weeks, group III: rats were given $300 \mathrm{mg} /$ kg BW costus root extract orally and daily for 8 weeks, and group IV: rats were given combination of valproate sodium and costus root extract. After 8 weeks, blood samples were collected to evaluate $\mathrm{T} 3, \mathrm{~T} 4$ and thyroid-stimulating hormone (TSH) levels. Thyroid gland samples were handled for light and electron microscopic investigation. The heights of follicular cells, area \% of collagen fibers and color intensity of thyroglobulin immunoreaction were statistically analyzed.
RESULTS: After being given valproate sodium as an induction, hormonal assay showed significant decrease in serum T3 and T4 and significant increase of TSH. Follicular and cellular alterations were shown by light and electron microscopes. Morphometric study revealed increased follicular cell height and area \% of collagen fibers and decreased color intensity of thyroglobulin. In contrast, costus root extract appeared to have a protective role against valproate sodium-induced thyroid injury. Most of the changes induced by valproate sodium were not observed after supplementation with the plant root extract.

CONCLUSION: Valproate sodium has serious effects on the function and structure of thyroid gland, and this study shows that costus root extract could have a protective effect against these effects.

KEYWORDS: valproate sodium, rat, thyrotoxicity, Saussurea lappa

Indones Biomed J. 2020; 12(4): 304-12

\section{Introduction}

Valproate sodium is one of the most recommended anti-epileptic drugs for treating epilepsy, post-traumatic stress disorder, anorexia nervosa, migraine, anxiety disorder, and bipolar disorder.(1) Despite its efficiency and extensive use, it is associated with severe side effects that may threaten life of patients if not taken care of in time. Many researchers have found that valproate sodium causes adverse effects such as hepatotoxicity, nephrotoxicity, pancreatitis, teratogenicity, thrombocytopenia and platelet aggregation.(2,3,4) Moreover, it has adverse effects on the endocrine system, including thyroid functions.(5)

The hypothesized mechanism behind these destructive effects is the oxidative stress produced by the drug and insufficient antioxidants.(6) Valproate sodium is metabolized to give reactive metabolites, which form covalent bonds with the biological macromolecules, like lipids, proteins, and DNA causing systemic toxicity.(6) Moreover, it blocks neuronal ion channels (7), improves $\gamma$-aminobutyric acid (GABA) transmission and irritates glutamate receptors. 
Comparable neurochemical mechanisms are involved in the interaction of this drug with the synthesis of thyrotropin releasing hormone (TRH), which regulate the formation and secretion of thyroid stimulating hormone (TSH). It also stimulates cytochrome P450 isoenzymes, leading to disturbance in hormone metabolism.(8) Elevated TSH and reduced thyroxine (T4), triiodothyronine (T3) and thyroidbinding globulin concentrations were found in patients treated with valproate sodium.(5) Few data were found regarding the effect of valproate sodium on thyroid gland tissues, in contrast to its effect on thyroid hormones.(9)

In order to defeat the harmful effect of free radicals and to decrease the injury by oxidants, numerous natural substances have been used as antioxidants. Lately, there has been renewed interest in the use of medicinal plants in the treatment of endocrine disorders and the reduction of oxidative stress. $(10,11)$ Saussurea lappa (costus) is one of the medicinal plants that is rich in antioxidants. It is antihepatotoxic, anti-inflammatory, anti-tumor, anti-fungal, antidiabetic, anthelmintic, antimicrobial and immunostimulant. Also, it modulates the serum parameters in both hypo-and hyper-thyroid mice.(11)

Based on the above data, the present study aimed to investigate the possible protective effects of costus extract in improving thyroid hormonal abnormalities, histological changes and thyroglobulin expression in thyroid gland of adult male albino rats treated with valproate sodium.

\section{Methods}

\section{Preparation of Costus Root Extract}

Costus roots were obtained from a herbal store in Cairo, Egypt. It was identified by a specialized taxonomist in Botany Department, Faculty of Science, Beni-Suef University. Costus roots was grinded then extracted.(12) Briefly, $50 \mathrm{~g}$ of the plant roots were extracted using 200 $\mathrm{mL}$ of $70 \%$ ethanol at room temperature, macerated for 72 hours, then filtered three times and evaporated to obtain a crude costus extract. The final product was $15 \%$ of the raw herb root weight. The extract was liquefied in distilled water as a vehicle before giving to rats.

\section{Experimental Design}

Eighty healthy adult male albino rats (Rattus norvegicus) weighing 130-150 g were used in the present study. The animals were purchased from the animal house of Research Institute of Ophthalmology, Giza, Egypt. This study was approved by Institutional Animal Care and Use Committee
Beni-Suef University (BSU-IACUC (No. 020-130)). The rats were put under normal day and light situations, and housed in stainless steel cages with free access to drinking water and food. In accordance with the principles of laboratory animal care, they were given human care.

After 1 week of acclimatization, rats were divided into four equivalent groups, including untreated control group (G-I), which received distilled water for 8 weeks; group II (G-II) which received $200 \mathrm{mg} / \mathrm{kg}$ BW valproate sodium (Depakine) orally and daily for 8 weeks (13); group III (G-III) which received costus root extract (300 mg $/ \mathrm{kg} \mathrm{BW}$ ) orally and daily by gastric tube for 8 weeks (14); and Group IV (G-IV) which received the combination of valproate sodium and costus root extract at the same dose and period as in G-II and G-III. Each tablet of $200 \mathrm{mg}$ valproate sodium (Sanofi Aventis, Cairo, Egypt) was dissolved in $10 \mathrm{~mL}$ distilled water, and each rat received $1.5 \mathrm{~mL}$ of the previously formed solution.

After 8 weeks, blood samples were collected from all groups for hormonal assay, after that rats were sacrificed. Thyroid samples were prepared for histological, thyroglobulin immunohistochemical, and ultrastructural studies.

\section{Hormonal Assay}

Blood samples, without anticoagulant, were centrifuged to separate the serum. The obtained serum was kept at $-20^{\circ} \mathrm{C}$ until analysis. The concentrations of serum T4 (15), T3 (16), and thyrotropin (TSH) (17) of all animals were estimated.

\section{Histological Study}

Left thyroid gland, from all groups, were fixed in neutral buffered formalin $(10 \%)$ for 24 hours. The samples were routinely processed to prepare paraffin sections $(5 \mu \mathrm{m}$ thickness) then stained with Haematoxylin and Eosin (H\&E) to confirm the histological details.(18) Other sections were stained with Masson's trichrome stain to determine the collagen fibers in the tissue.(19)

\section{Immunohistochemical Evaluation of Thyroglobulin} Thyroglobulin immunostaining was done by mouse monoclonal antibody kit (Thermo Scentific/Lab Vision Corporation, Fermont, USA) consistent with the avidinbiotin-peroxidase complex (ABC) technique. Five $\mu \mathrm{m}$ thick sections were cut from the prepared paraffin tissues then moved to positively charged glass slides. The sections were dewaxed, rehydrated, blocked by hydrogen peroxide and antigen retrieval by microwave. Incubation of the slides was done using the primary antibody at $2-8^{\circ} \mathrm{C}$ overnight. 
Incubation by secondary antibody was done by the chromogen, diaminobenzidine substrate. Finally, the slides were stained by hematoxylin as a counterstain and washed using distilled water and phosphate buffered saline (PBS). (20) In the negative control, phosphate buffer solution was used instead of the primary antibody. Thyroglobulin immunohistochemical expression appeared in the follicular colloid as brown stain and was evaluated according to the intensity of the stain.(21)

\section{Ultrastructural Study}

Specimens from the right thyroid gland $(1-3 \mathrm{~mm})$ were immediately fixed in freshly prepared 3\% buffered glutaraldehyde ( $\mathrm{pH} 7.4$ ) for 4 hours at $4^{\circ} \mathrm{C}$, washed with phosphate buffer $(\mathrm{pH} 7.4)$, post fixed in $1 \%$ osmium tetraoxide in the same buffer for 1 hour at $4^{\circ} \mathrm{C}$. The specimens were dehydrated using ascending grades of ethyl alcohol then put in propylene oxide at room temperature for $30 \mathrm{~min}$, impregnated in propylene oxide and resin mixture (1:1 for 24 hours) and in a pure resin for another 24 hours. Then, the thyroid specimens were put in fresh resin at $60^{\circ} \mathrm{C}$ for 24 hours. $(22,23)$ Semi-thin sections $(1.0 \mathrm{~mm})$ were cut using an ultramicrotome, stained with toluidine blue, and examined by light microscope. Ultrathin sections (70$90 \mathrm{~mm}$ ) were prepared using diamond knives, mounted on copper grids and stained with uranyl acetate and lead citrate $(22,23)$ then examined with a transmission electron microscope (JEM 1200 EXII, JEOL, T okyo, Japan) operated at $60 \mathrm{kV}$ at the Faculty of Science, Ain Shams University.

\section{Morphometrical Study}

The height of the follicular cells, area $\%$ of collagen fibers and color intensity of thyroglobulin immunoreaction were measured using a Leica Qwin 500 Image Analyzer Computer System (Leica, Cambridge, UK) at the Histology Department, Faculty of Medicine, Ain Shams University,
Egypt. Ten different and non-overlapping fields for each one of the mentioned parameters were investigated in each group at a magnification of X 400 .

\section{Statistical Analysis}

The obtained data were symbolized as mean \pm standard error (mean \pm SE). The data were analyzed using SPSS program, version 20 (IBM Corporation, New York, USA). One-way analysis of variance test (ANOVA) followed by the least significant difference (LSD) were used to compare between the different groups. The results were statistically significant when the probability ( $p$-value) less than $0.05(p<0.05)$.

\section{Results}

\section{Serum T3, T4 and TSH Level}

The hormonal level of G-II showed significant decrease in T3 and T4 and significant elevation in TSH level in comparison to G-I and G-III. Moreover, G-IV showed significant increase in serum $\mathrm{T} 3$ and $\mathrm{T} 4$ and significant decrease in TSH level in comparison to G-II (Table 1).

\section{Histopathological Observation}

G-I displayed thyroid follicles lined by single layer of simple cuboidal epithelium with rounded nuclei (Figure 1A, Figure 1B). The follicles separated from each other by thin connective tissue septa. Their lumina are filled with homogenous acidophilic colloid (Figure 1A, Figure 1B). Sections from G-III showed similar histological structure (Figure 2A, Figure 2B) to that of G-I.

G-II showed irregular follicles with an obvious increase in their size (Figure 1C, Figure 1D). Many blood vessels appeared dilated and congested (Figure 1C). In many follicles, several layers of follicular cells were seen (Figure 1C). Most follicles lined by very high and vacuolated cells with karyolitic nuclei (Figure 1D). Decreased or no colloid

Table 1. Hormonal assay and morphometric analysis of the thyroid gland specimens from different groups.

\begin{tabular}{lcccc}
\hline \multicolumn{1}{c}{ Groups } & GI & GII & GIII & GIV \\
\hline T3 (U/L) & $50.21 \pm 1.15^{\mathrm{ab}}$ & $29.13 \pm 1.54^{\mathrm{c}}$ & $49.71 \pm 1.66^{\mathrm{b}}$ & $45.25 \pm 1.21^{\mathrm{d}}$ \\
$\mathrm{T} 4(\mathrm{U} / \mathrm{L})$ & $2.16 \pm 0.12^{\mathrm{ab}}$ & $0.64 \pm 0.15^{\mathrm{c}}$ & $2.11 \pm 0.11^{\mathrm{b}}$ & $1.54 \pm 0.13^{\mathrm{d}}$ \\
TSH $(\mathrm{mU} / \mathrm{L})$ & $3.22 \pm 0.14^{\mathrm{ab}}$ & $6.45 \pm 0.87^{\mathrm{c}}$ & $3.17 \pm 0.14^{\mathrm{b}}$ & $4.12 \pm 0.45^{\mathrm{d}}$ \\
Mean of follicular cells height $(\mu \mathrm{m})$ & $7.52 \pm 0.31^{\mathrm{a}}$ & $12.34 \pm 0.88^{\mathrm{c}}$ & $7.81 \pm 0.43^{\mathrm{ab}}$ & $8.38 \pm 0.37^{\mathrm{bd}}$ \\
Mean of collagen area $(\%)$ & $2.57 \pm 0.51^{\mathrm{a}}$ & $5.94 \pm 0.79^{\mathrm{c}}$ & $2.70 \pm 0.62^{\mathrm{ab}}$ & $3.67 \pm 0.45^{\mathrm{bd}}$ \\
Mean of thyroglobulin color intensity & $65.11 \pm 1.32^{\mathrm{a}}$ & $30.25 \pm 1.56^{\mathrm{c}}$ & $64.99 \pm 1.25^{\mathrm{ab}}$ & $63.84 \pm 0.96^{\mathrm{ad}}$ \\
\hline
\end{tabular}

Data are represented as mean \pm SE. The values with different superscript letters in a row are significantly different $(p<0.05)$. 

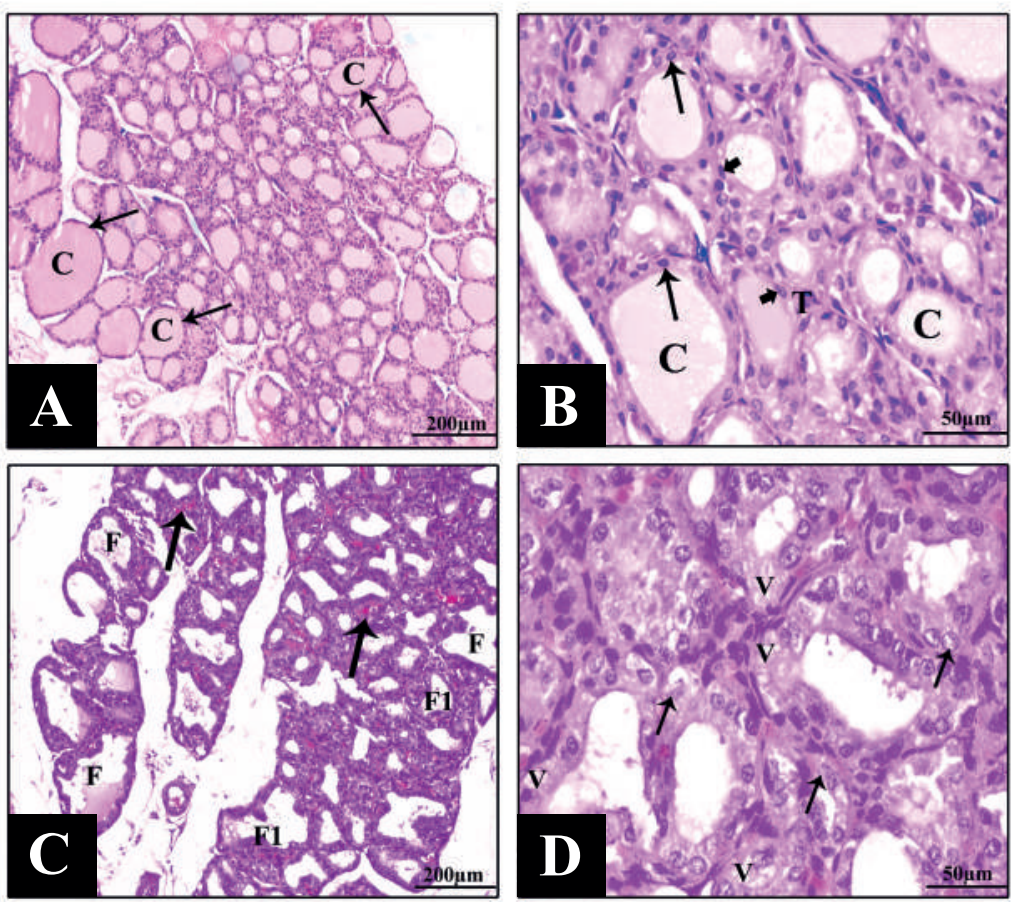

Figure 1. Photomicrographs of thyroid tissues of rats (H\&E stain). A: G-I showing many regular follicles (arrows) with homogenous acidophilic colloid (C). B: G-I showing the thyroid follicles with acidophilic colloid (C) are separated by interstitial tissues (T) and lined with flattened to cuboidal cells with oval (thick arrows) to rounded (thin arrows) nuclei. C: G-II showing many enlarged and irregular follicules (F) with few or no colloid, some of the follicles (F1) lined by many layers of follicular cells, there are also congested and dilated blood vessels (arrows). D: G-II showing some follicular cells appeared swollen and vacuolated (V), others appeared with vacuolated or karyolitic nuclei (arrows). content was observed in many follicles with hyperemia between them (Figure 1C, Figure 1D).

In G-IV, many of the follicular cells seemed with normal height and the follicular lumen filled with homogenous acidophilic colloid (Figure 2C, Figure 2D). However, few follicles with vacuolated cells and few colloid were observed (Figure 2C, Figure 2D).

\section{Masson's Trichrome Stained Sections}

Thyroid sections of G-I (Figure 3A) and G-III (Figure 3C) revealed few collagen fibers in the connective tissue between the thyroid follicles. Extreme amount of collagen fibers was observed in between the thyroid follicles of G-II (Figure 3B). Few collagen fibers were observed in between the thyroid follicles of G-IV (Figure 3D).
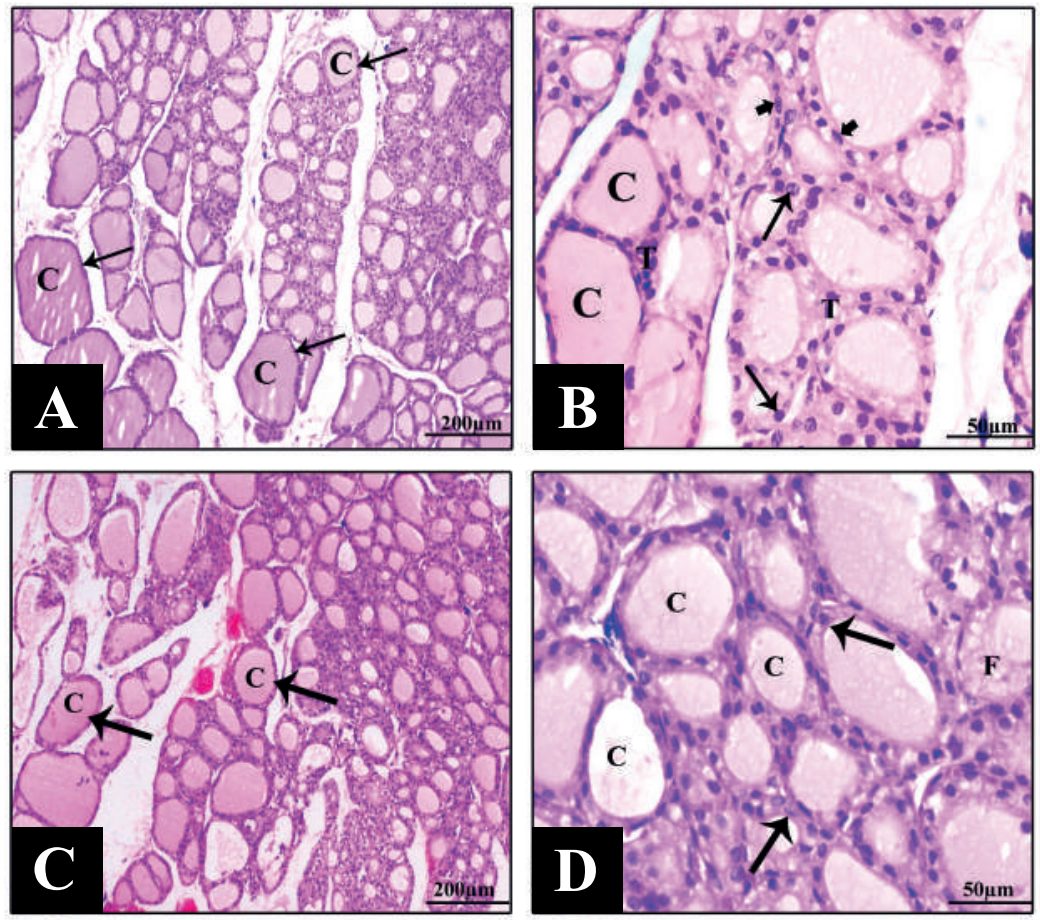

Figure 2. Photomicrographs of thyroid tissues of rats (H\&E stain). A: G-III showing many regular follicles (arrows) with homogenous acidophilic colloid (C). B: G-III showing the thyroid follicles with acidophilic colloid are separated by interstitial tissues (T) and lined with flattened to cuboidal cells with oval (thick arrows) to rounded (thin arrows) nuclei. C: G-IV showing many regular follicles with normal size (arrows) and follicular colloid (C). D: G-IV showing Follicular cells with normal height (arrows), oval to rounded nuclei, colloid (C) and normal cytoplasm and few follicular cells $(\mathrm{F})$ with vacuolated cytoplasm. 

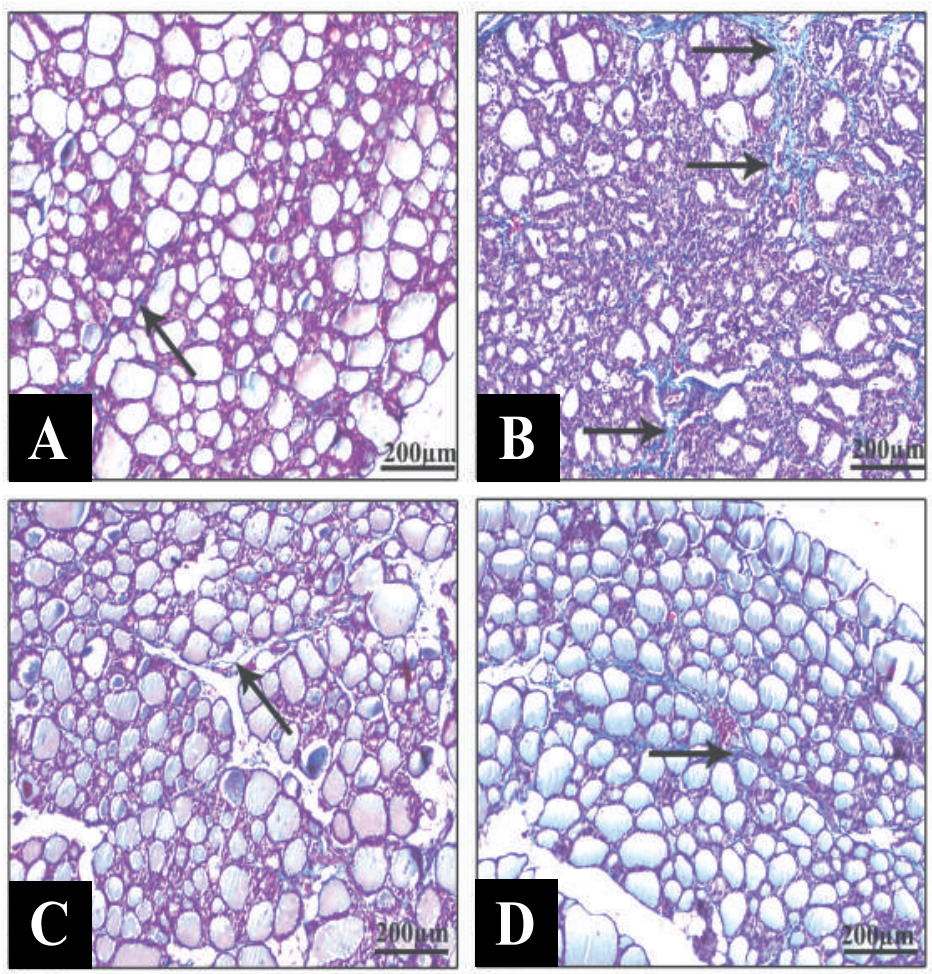

Figure 3. Photomicrographs of thyroid tissues in the experimental groups (Masson's trichrome stain). A: G-I showing very few collagen fibers between the thyroid follicles (arrow). B: G-II showing extreme amount of collagen fibers in between the thyroid follicles (arrows). C: G-III showing very few collagen fibers between the thyroid follicles (arrow). D: G-IV showing few collagen fibers between the thyroid follicles (arrow).

\section{Thyroglobulin Expression}

Thyroid sections of G-I (Figure 4A) and G-III (Figure 4C) displayed strong positive thyroglobulin staining intensity. Sections from G-II showed weak thyroglobulin expression in the follicular colloid in comparison to G-I and G-III (Figure 4B). On the other hand, thyroid sections from G-IV revealed marked brownish thyroglobulin expression in the follicular colloid (Figure 4D).

\section{Histomorphometrical Analysis}

The mean heights of follicular cells and the area \% of collagen fibers of G-II were significantly increased in
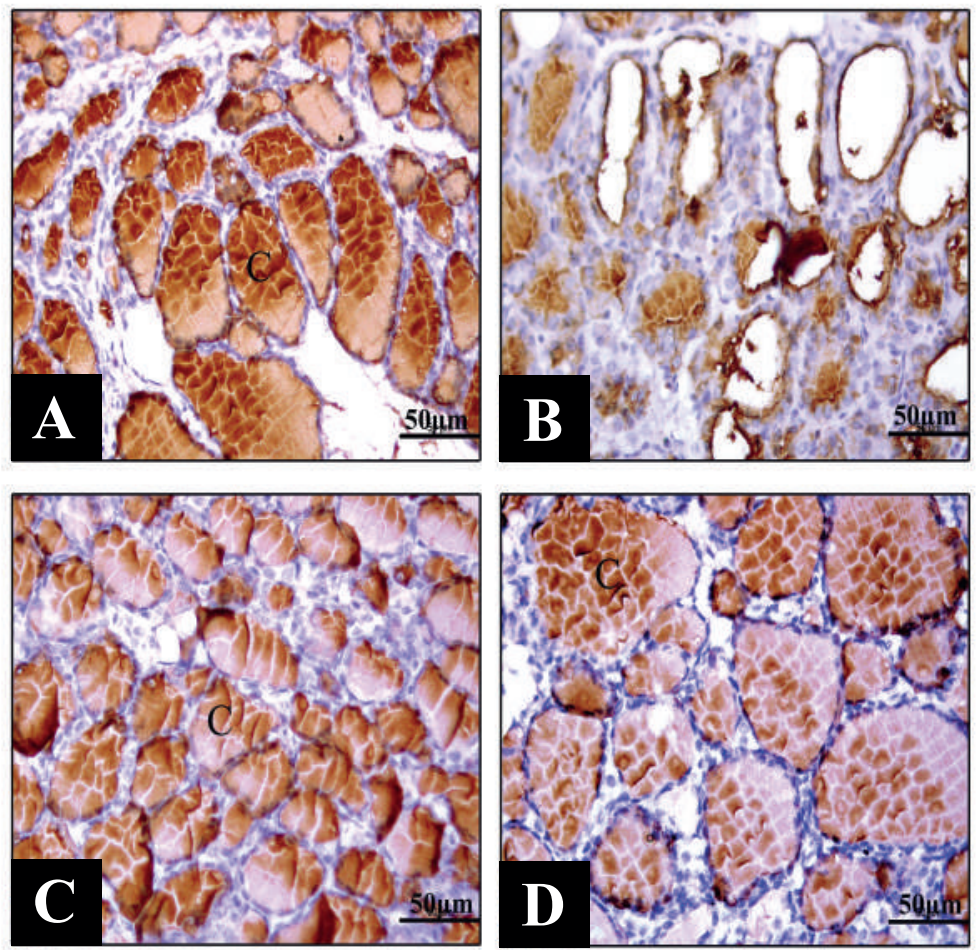

Figure 4. Thyroglobulin immunohistochemical examination in thyroid tissues. A: G-I showing strong positive thyroglobulin staining intensity in the follicular colloid (C). B: G-II showing weak thyroglobulin expression in the follicular colloid. C: G-III showing strong thyroglobulin expression in the follicular colloid (C). D: G-IV showing marked brownish thyroglobulin expression in the follicular colloid (C). 
comparison to that of the G-I. In contrast, the color intensity of thyroglobulin immunoreaction was significantly decreased. G-IV showed significant decrease in the epithelial height, area $\%$ of collagen and significant increase in thyroglobulin intensity compared to G-II (Table 1).

\section{Ultrastructural Observation}

Thyroid gland from G-I showed follicular cells with regular euchromatic nuclei. The cytoplasm has rough endoplasmic reticulum with paralleled cisternae, dense lysosomal granules, mitochondria and Golgi bodies (Figure 5A). The apical membrane of the follicular cells appeared with small microvilli projecting into the lumen. The apical part of cytoplasm has secretory vesicles (Figure 5A). Thyroid gland from G-III showed similar structure (Figure 5E).

G-II showed highly vacuolated follicular cells. Many collagen fibers and mast cells with dense granules were observed in the interfollicular connective tissue (Figure 5B). Cytoplasmic disorganization and dilated irregular cisternae of endoplasmic reticulum with amorphous materials and vacuolated mitochondria were observed (Figure 5C). Many follicular cells appeared with irregular nuclei and clumping of their heterochromatin at the periphery, while others showed shrinked or karyolytic nuclei and disrupted basal lamina (Figure 5C, Figure 5D).

Thyroid gland of G-IV showed marked improvement in the ultrastructure in comparison to the G-II. The thyrocytes showed nearly normal nucleus, mitochondria, rough endoplasmic reticulum, apical and basal membranes (Figure 5F).

\section{Discussion}

Valproate sodium may cause hormonal system disturbance and the interaction of this drug with thyroid, gonadal and adrenal axis requires attention.(24) In the present study, administration of valproate sodium to rats caused a significant decrease in T4 and T3 while TSH was significantly elevated this might indicate a state of hypothyroidism. These results were in agreement with some investigators who reported lower $\mathrm{T} 4$ and increased
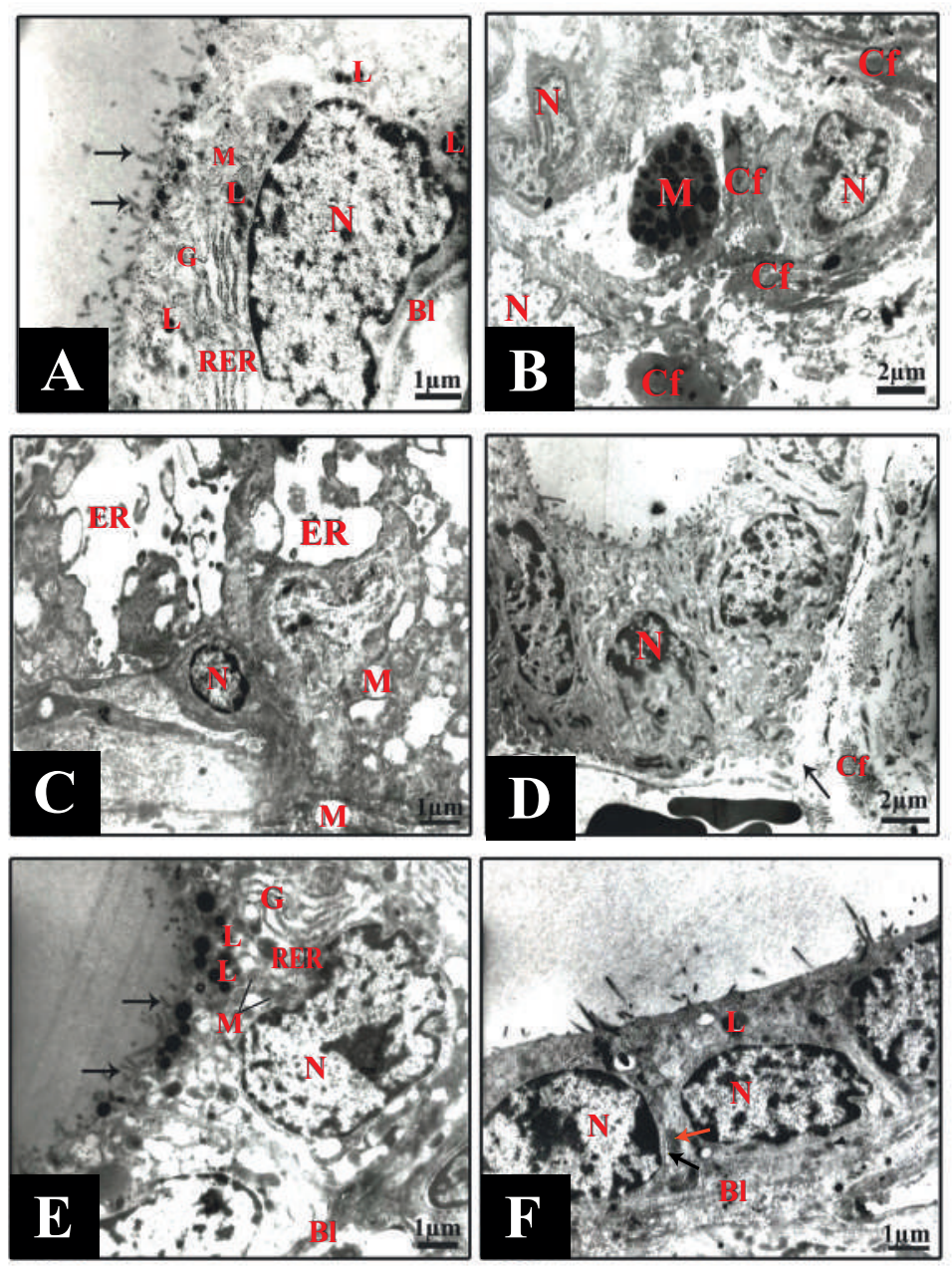

Figure 5. Electron micrographs of thyroid cells in the experimental groups. A: G-I showing follicular cells resting on a basal lamina $(\mathrm{Bl})$ and having short apical microvilli projecting into the lumen (arrows) and euchromatic nucleus (N). The cytoplasm has well developed parallel cisternae of rough endoplasmic reticulum (RER), Golgi apparatus (G), lysosomes (L), and mitochondria (M). B: G-II showing a mast cell (M) with dense granules and abundant collagen fibers (Cf) in the interfollicular connective tissue. There are irregularity found in the nuclear membranes (N). C: G-II showing endoplasmic reticulum (ER) filled with flocculent materials and extensively dilated cisternae, shrinkage heterochromatic nucleus (N) and swollen, vacuolated mitochondria (M). D: G-II showing irregular and karyolytic nucleus $(\mathrm{N})$, disrupted basement membrane (arrow) and collagen fibers (Cf). E: G-III showing follicular cells resting on a basal lamina (Bl) and having short apical microvilli projecting into the lumen (arrows) and euchromatic nucleus $(\mathrm{N})$. The cytoplasm has well developed parallel cisternae of rough endoplasmic reticulum (RER), Golgi apparatus (G), lysosomes (L), and mitochondria (M). F: G-IV showing cuboidal cells with apical microvilli (arrows), euchromatic rounded or oval nuclei $(\mathrm{N})$ and disrupted basal lamina (Bl). The cytoplasm displays nearly normal endoplasmic reticulum (black arrow), mitochondria (red arrow), and lysosomes (L). 
TSH levels in valproate sodium treated rats.(9) Moreover, increase in TSH level was obvious in children treated with valproate sodium, accounting for $26 \%$ of patients with subclinical hypothyroidism.(25)

The suggested mechanisms for hypothyroidism with valproate sodium include improved metabolism and/or altered protein binding or disturbing the function of the hypothalamic-pituitary-thyroid axis. $(26,27)$ Valproate sodium stimulates hepatic CYP450 enzyme with subsequent enhanced thyroid hormone metabolism, thus reducing serum T3 and T4 concentration.(26) Furthermore, valproic acid may result in zinc and selenium deficiencies, which are important for thyroid hormones synthesis.(28) Consequent disturbance of hypothalamic-pituitary axis regulation of thyroid hormone production occurs, as T3 or T4 is not synthesized to apply a negative feedback, and synthesis and secretion of TSH increase.(27) Moreover, GABAstimulating properties of valproic acid inhibit somatostatin release, which inhibits TSH secretion leading to its increase in the serum.(29)

The changes in thyroid functions in G-II were more established by histological and ultrastructural investigation of follicular cells, which showed apparent alterations. These results agree with a previous study which has shown a significant elevation in the epithelial height in valproate treated rats.(9) Moreover, follicular cells hypertrophy and cellular stratification were also detected, which may be related to the elevation in TSH level.(30)

Earlier authors elucidated that in hypothyroidism, thyroid follicles are distended with colloid. As T3 or T4 is not synthesized to apply a negative feedback and synthesis and secretion of TSH increase leading to thyroid growth and vascularization. Accordingly, the height of the epithelial cells of the thyroid gland increased.(30) Moreover, other investigators reported that increase in the thyroid follicular diameter indicated thyroid hypoactivity.(31)

Weak expression of thyroglobulin observed in G-II was confirmed statistically in the present study. Thyrocytes respond to increased TSH by rapid and continuous elimination of thyroglobulin from the follicular lumen as a compensation for the decreased blood thyroid hormones resulting in more colloid vacuolations. Continuous colloid endocytosis at a greater rate than synthesis leading to progressive reduction of colloid and cytoplasmic vacuolation.(32)

Ultrastracturally, the thyrocytes of G-II revealed disorganization of the cytoplasmic contents, dilated endoplasmic reticulum, vacuolated mitochondria, nuclear alteration and collagen fibers deposition. These results are consistent with other studies which have shown that valproate aggravated the histological structure of the thyroid (9) and renal cortex and increased collagen deposition in the renal tissues.(3)An earlier study reported that ROS activates nuclear transcription factor $\mathrm{\kappa B}$ leading to inflammation, apoptosis, fibrosis, and increased collagen production and affected the vascular wall with consequent dilatation and blood vessel congestion.(3,33) Nuclear alterations were resulted from the over stimulation of thyroid gland that leads to the breakdown of DNA and chromatins.(4) The cytoplasm of many follicular cells appeared with numerous electron lucent empty areas. Some researchers attributed the existence of these areas to the swollen mitochondria and dilated endoplasmic reticulum.(34) They also connected the existence of collagen fibers to thyroid gland fibrosis that might occur in late phases of thyroid injury. The detected dilatation of rough endoplasmic reticulum (RER) cisternae might be sign of altered protein synthesis initiated by impaired stimulation of TSH receptor in thyroid cells. RER dilatation might be due to preservation of protein that could not be handled, folded, or moved to proper sites. (35) Disturbance in protein synthesis inhibits the apoptosis inhibitors production and loss of vital proteins, which are essential for cellular homeostasis, leading to deterioration of the cells.(36)

G-IV showed normal epithelial height of follicular cells, normalization of collagen, and increased thyroglobulin expression in the majority of thyroid sections. The serum levels of T3, T4 were significantly increased and TSH level was significantly decreased as compared to G-II. Furthermore, there was a noticeable histological and ultrastructural enhancement. These results could be related to the antioxidant effect of costus root extract resulting in preserving the thyroid from valproate effects. Limited studies have studied the antioxidant role of costus root extract. Its antioxidant effect may attribute to its active constituents, namely flavonoids, anthraquinone, and many terpenes such as alpha-and beta-amyrin which inhibit NF-k $\beta$ activation.(37) Costus extract is a cytoprotective agent as it displayed high free radical scavenging effect that induces extensive injury to cell constituents.(11) Additional support came from another study in which costus improved blood alterations in hypo- and hyperthyroidism demonstrating ameliorative therapeutic effect of costus during thyroid illnesses.(11) Moreover, thyroid follicles from G-IV showed neither hyperplasia nor hypertrophy. This could be related to the antiproliferative property of costus root extract.(38) 


\section{Conclusion}

Costus root extract displayed marked improvement in the functional, histological and ultrastructural alterations of the thyroid follicles induced by valproate sodium. So; the present results could recommend that the costus root extract can be used as an adjuvant cotherapy in epileptic patients.

\section{References}

1. Panayiotopoulos CP, editor. A Clinical Guide to Epileptic Syndromes and their Treatment. United Kingdom: Springer Healthcare; 2010.

2. Ibrahim MA. Evaluation of hepatotoxicity of valproic acid in albino mice, histological and histoistochemical studies. Life Sci J. 2012; 9: 153-9.

3. Hamouda MH, Abdel Aal FS, El-Mashad FH. Effect of sodium valproate on the structure of the renal cortex of adult male Albino rat and the role of cinnamon. Al-Azhar Med J. 2019; 48: 1-28.

4. Shakya RD, Hoque MK, Sapkota AS, Gupta PK. Differential hepatotoxic effects of sodium valproate at different doses in albino rats. Kathmandu Univ Med J. 2018; 61: 78-82.

5. Hamed SH. The effect of anti-epileptic drugs on thyroid hormonal function: causes and implications. Expert Rev Clin Pharmacol. 2015; 8: 741-50.

6. Ercegovac M, Jovi N, Simi T, Besla-Bumbairevi L, Soki D, SaviRadojevi A, et al. Antiepileptic drugs affect protein, lipids and DNA oxidative damage and antioxidant defense in patients with epilepsy. J Med Biochem. 2013; 32: 121-30.

7. Rogawski MA, Löscher W, Rho JM. Mechanisms of action of antiseizure drugs and the ketogenic diet. Cold Spring Harb Perspect Med. 2016; 6: a022780. doi: 10.1101/cshperspect. a022780.

8. Sepahi S, Riahi-Zangani B, Ghorani-Azam A. Effect of valproic acid on metabolic status and endocrine system in pediatric patients with epilepsy: systematic literature review. Rev Clin Med. 2017; 4: 7-13.

9. Elbaramawi MI. Effect of anti-epileptic drugs on the thyroid gland in adult Albino rats: hormonal assay, histological and morphometric study. Egypt J Histol. 2014; 38: 10-20.

10. Abdul-Hamid M, Salah M. Intervention of ginger or propolis ameliorates methotrexate-induced ileum toxicity. Toxicol Ind Health. 2016; 32: 313-22.

11. Bolkiny Y, Tousson E, El-Atrsh A, Akela M, Farg M. Costus root extract alleviates blood biochemical derangements of experimentally-induced hypo- and hyperthyroidism in mice. Annu Res Rev Biol. 2019; 31: 1-10.

12. Srivastava S, Singh P, Jha KK, Mishra G, Srivastava S, Khosa RL. Evaluation of anti-arthritic potential of the methanolic extract of the aerial parts of Costus speciosus. J Ayurveda Integr Med. 2012; 3: 204-8.

13. Töllner K, Wolf S, Löscher W, Gernert M. The anticonvulsant response to valproate in kindled rats is correlated with its effect on neuronal firing in the substantia nigra pars reticulata: a new mechanism of pharmacoresistance. J Neurosci Res. 2011; 31: 16423-34.

14. Vogel GH, Vogel WH. Drug Discovery and Evaluation. Berlin: Spinger Verlag; 1998.

15. Smals AGH, Ross AH, Kloppenborg PWC. Dichotomy between serum free triiodothyronine and free thyroxine concentrations in familial thyroxine-binding globulin deficiency. J Clin Endocrinol. Metab. 1981; 53: 917-22

16. Larsen PR. Thyroid-pituitary interaction: feedback regulation of thyrotropin secretion by thyroid hormones. N Engl J Med. 1982; 306: 23-32.

17. Mandel SJ, Brent GA, Larsen PR. Levothyroxine therapy in patients with thyroid disease. Ann Intern Med. 1993; 119: 492-502.

18. Bancroft J, Gamble M. Theory and Practice of Histolological Technique. 5th edition. London: Churchil Livingstone; 2002.

19. Pearse AG. Histochemistry, Theoretical and Applied Vol. 11. 3rd edition. Boston: Little Brownand; 1972.

20. Ramos-Vara JA, Beissenherz ME. Optimization of immunohistochemical methods using two different antigen retrieval methods on formalin-fixed, paraffin-embedded tissues: Experience with 63 markers. J Vet Diagn Invest. 2000; 12: 307-11.

21. Wang YF, Liu B, Fan XS, Rao Q, Xu Y, Xia QY, et al. Thyroid carcinoma showing thymus-like elements: A clinicopathologic, immunohistochemical, ultrastructural and molecular analysis. Amer J Clin Path. 2015; 143: 223-33.

22. Bozzola JJ, Rusell LD. Electron Microscopy Principles and Techniques for Biologists. 2nd edition. Boston: Jones and Bartlett Publisher; 1999.

23. Glauert AM, Lewis PR. Biological Specimen Preparation for Transmission Electron Microscopy. Vol. 17. London: Portland Press; 1998

24. Røste LS, Taubøll E, Mørkrid L, Bjørnenak T, Saetre ER, Mørland T, et al. Antiepileptic drugs alter reproductive endocrine hormones in men with epilepsy. Eur J Neurol. 2005; 12: 118-24.

25. Eirís-Puñal J, Del Río-Garma M, Del Río-Garma MC, LojoRocamonde S, Novo-Rodríguez I, Castro-Gago M. Long-term treatment of children with epilepsy with valproate or carbamazepine Corp; 2011.may cause subclinical hypothyroidism. Epilepsia. 1999; 40: 1761-6.

26. Benedetti MS, Whomsley R, Baltes E, Tonner F. Alteration of thyroid hormone homeostasis by anti-epileptic drugs in humans: Involvement of glucuronosyltransferase induction. Eur J Clin Pharmacol. 2005; 61: 863-72

27. Verrotti A, Scardapane A, Manco R, Chiarelli F. Antiepileptic drugs and thyroid function. J Pediatr Endocrinol Metab. 2008; 21: 401-8.

28. Castro-Gago M, Novo-Rodri'guez MI, Go'mez-Lado C, Rodri' guezGarc1'a J, Rodr1'guez-Segade S, Eir1's-Puñal J. Evolution of subclinical hypothyroidism in chil-dren treated with anti-epileptic drugs. Pediatr Neurol. 2007; 37: 426-30.

29. Sibarani JJ, Deliana M, Saing JH. Valproate use and thyroid dysfunction in children with idiopathic epilepsy. Paediatrica Indonesiana. 2018; 58: 192-7.

30. Wier FA, Farley CL. Clinical controversies in screening women for thyroid disorders during pregnancy. J Midwifery Womens Health. 2006; 51: 152-8.

31. Ganong WF. Review of Medical Physiology. 22nd edition. New York: McGraw-Hill; 2005.

32. Mahmoud T, Qureshi IZ, Iqabi MJ. Histopathological and biochemical changes in rat thyroid following acute exposure to hexavalent chromium. Histol Histopathol. 2010; 25: 1355-70.

33. Rodrigo R, Trujillo S, Basco C, Orellena M, Thielemann L, Araya J. Changes in $(\mathrm{Na}+\mathrm{K})$-adenosine triphosphate activity and ultrastructure of lung and kidney associated with oxidative stress induced by acute ethanol intoxication. Chest. 2002; 121: 589-96.

34. Teng X, Shan Z, Teng W, Fan C, Wang H, Guo R. Experimental study on the effects of chronic iodine excess on thyroid function, structure, and autoimmunity in autoimmune-prone NOD.H-2h4 mice. Clin Exp Med. 2009; 9: 51-9. 
35. Kim I, Xu W, Reed JC. Cell death and endoplasmic reticulum stress: Disease relevance and therapeutic opportunities. Nat Rev Drug Discov. 2008; 7: 1013-30.

36. Rajkovic V, Matavulj M, Johansson O. Light and electron microscopic study of the thyroid gland in rats exposed to power-frequency electromagnetic fields. J Exp Biol. 2006; 209: 3322-8.
37. Alnahdi HS. Injury in metabolic gland induced by pyrethroid insecticide could be reduced by aqueous extract of Sassura lappa. Int J Pharm Res Allied Sci. 2017; 6: 86-97.

38. Rahmana MA, Hongb J, Huha S. Antiproliferative properties of Saussurea lappa Clarke root extract in SH-SY5Y neuroblastoma cells via intrinsic apoptotic pathway. Anim Cells Syst. 2015; 19: $119-26$. 